\title{
Malzeme Modellerinin Sac Metal Sonlu Elemanlar Analizi Tahmin Performansına Etkisinin Değerlendirilmesi
}

\section{Evaluation of Material Model Effect on Sheet Metal Forming Finite Element Analysis Prediction Performance}

\author{
Özlem KÖLEOĞLU GÜRSOY ${ }^{1}$, Emre ESENER ${ }^{2 *}$
}

Geliş / Received: 05/04/2019

\author{
Revize / Revised: 29/04/2019
}

Kabul / Accepted: 02/05/2019

$\ddot{O}$

z- Sac metaller ağırlık/dayanım oranlarından ötürü başta otomotiv olmak üzere pek çok sektörde tercih edilmektedirler. İnce malzemelerle çalışıldığından ve karmaşık ürün formları hedeflendiğinden sac metal şekillendirme prosesleri genelde karmaşık prosesler olarak karşımıza çıkmaktadırlar. Çoğunlukla seri üretim ürünü olarak tercih edilmelerinden dolayı sac metal kalıp takımları oldukça pahalıdırlar. Bu nedenle kalıp takımlarının tasarım aşamasında telafi edilme zorunluluğu ortaya çıkmıştır. Günümüzde bu amaçla en sık kullanılan yöntem sonlu elemanlar analizidir. Sonlu elemanlar analizlerinin ise tahmin hassasiyetlerinin yüksek olması gerekmektedir. Hassasiyete etki eden en baskın parametre ise malzemelerin plastik davranışının tanımlandığı malzeme modelleridir. Bu çalışmada sonlu elemanlar malzeme modellerinin tahmin performansına etkisi incelenmiş olup bu amaçla derin çekme, kare kutu çekme ve V-kalıpta eğme prosesleri 4 farklı malzeme (DP600, DP980, DC05, AA5754) için incelenmiştir. Çalışmada izotropik malzeme-izotropik pekleşme kabulü yapan (Power Law), anizotropik malzemeizotropik pekleşme kabullü (Hill-48, Barlat-89) ve anizotropik malzeme - kinematik pekleşme kabullü (Yoshida Uemori) dört farklı malzeme modeli kullanıııştır. Gerçekleştirilen simülasyon sonrasında sonuçlar deneysel verilerle kıyaslanarak sonlu elemanlar tahmin performansları ortaya konulmuştur. En hassas tahminlerin tüm modellerde kinematik pekleşme kabullü malzeme modeli ile elde edildiği tespit edilmiştir.

Anahtar Kelimeler- Sac Metal Şekillendirme, Sonlu Elamanlar Analizi, Plastisite Modelleme, Mekanik Özellik

$A$

bstract- Sheet metals have a wide usage area due to their weight to strength ratios especially in automotive industry. Sheet metal forming processes can be described as complex manufacturing processes for working with thin materials by complex product forms, and die tools are expensive since sheet metal forming processes are in use at mass production. Therefore, sheet metal die tools must be compensate in design stages. Today, finite element analysis (FEA) are in use widely for this purpose. However, prediction performance of FEAs must be accurate. Material models which defines the plastic behavior of the materials effects the accuracy significantly. In this study, the effect of material models on finite element analysis prediction performance was investigated for this purpose deep drawing, square cup drawing, and V-die bending processes were studied using 4 different materials (DP600, DP980, DC05, AA5854). In the study, material models are used as isotropic material-isotropic hardening assumption (Power Law), anisotropic material-isotropic hardening assumption (Hill-48, Barlat-89), and anisotropic material-kinematic hardening assumption (Yoshida-Uemori). Each process was simulated using 4 different material models, than simulation results were compared with experimental studies. The most accurate results were obtained with kinematic hardening material model for all processes.

Keywords- Sheet Metal Forming, Finite Element Analysis, Plasticity Modelling, Mechanical Proper

1İletişim: okoleoglu@gmail.com (https://orcid.org/0000-0001-8638-1817)

Makine Mühendisliği Bölümü, Bilecik Şeyh Edebali Üniv, Gülümbe Kampüsü, Merkez, Bilecik

${ }^{2 *}$ Sorumlu yazar iletişim: emre.esener@bilecik.edu.tr (https://orcid.org/0000-0001-5854-4834)

Makine Mühendisliği Bölümü, Bilecik Şeyh Edebali Üniv, Gülümbe Kampüsü, Merkez, Bilecik 


\section{I.GİRIŞ}

Plastik şekil verme yöntemi bir malzemeyi akma gerilmesinin üzerinde bir yükle şekil değişimine zorlayarak kalııı bir form elde edilmesini amaçlamaktadır. Bu kapsamda dövme gibi kütle şekillendirme yöntemlerinin yanında sac metal şekillendirme gibi düzlem gerilme problemleri de plastik şekil verme başlığı altında yer almaktadır. Sac metaller ağırlık/dayanım oranı avantajlarından dolayı özellikle otomotiv ve havacılık sektörlerinde sıklıkla tercih edilmektedir [1]. Sac metal şekillendirme yöntemleri ince malzemelerle çalışıldığından ve ürün geometrilerinin karmaşık olmasından dolayı içerisinde birçok değişkenin yer aldığı karmaşık problemler olarak karşımıza çıkmaktadır. Bir malzemenin hata olmaksızın şekil değiştirebilme kabiliyetine şekillendirilebilirlik denilmektedir. Şekillendirilebilirlik kavramı proses ve malzeme özellikleriyle doğrudan ilişkilidir. Proses parametrelerinden parça tutucu kuvvet, sürtünme koşulu, pres hızı ve kalıp geometrileri bir malzemenin şekillendirilebilirliğine en çok etki eden parametreler olarak öne çıkmaktadır [2-5].

Sac metal şekillendirme yöntemlerinde karşılaşılan hatalar genellikle yırtılma, kırışma, kulaklanma ve şekil bozukluğu olarak ortaya çıkmaktadır [6-8]. Bu hatalardan yırtılma hatası genellikle parça tutucu kuvvet ve kalıp hızından, kırışma ve kulaklanma hataları ise parça tutucu kuvvetten kaynaklanmaktadır [9-11]. Şekil bozukluğu hatası ise genellikle malzemenin mekanik özellikleri ile ilişkilidir [12]. Sac metal kalıp yüzeyleri geliştirilirken malzemede meydana gelebilecek bu hataların tasarım aşamasında elimine edilmesi gerekmektedir. Aksi takdirde bu değişimler deneme-yanılma gibi pahalı ve zaman kaybına neden olan yöntemlerle gerçekleştirilmektedir. Günümüzde bilgisayar teknolojisinin gelişimine paralel olarak proses tasarım aşamalarında genellikle bilgisayar destekli mühendislik araçları kullanılmaktadır. Bu kapsamda sonlu elemanlar analizleri mühendislik problemlerinin çözümünde en çok kullanılan yöntem olarak karşımıza çıkmaktadır. Sac metal sonlu elemanlar analizleri hem büyük deformasyonlarla uğraşıldığından hem de temas problemleri barındırdığından nonlineer problemlerdir [13]. Bu problemlerde tahmin hassasiyetinin yüksek olması proseste karar verme mekanizmalarındaki deneme-yanılma süresini doğrudan etkilemektedir. Bu kapsamda sonlu elemanlar analizleri açısından tahmin hassasiyetine yönelik çeşitli çalışmalar literatürde yer almaktadır [14-17]. Bu araştırmalar genellikle eleman boyutu üzerine yoğunlaşmaktadır [18]. Son zamanlarda yapılan çalışmalar ise malzemenin plastik davranışının modellenme etkisinin eleman boyutundan daha fazla olduğunu göstermektedir [19, 20].

Bu çalışmanın amacı sac metal şekillendirme proseslerinde malzemelerin plastik davranışını modelleyen plastisite modellerinin sonlu elemanlar tahmini üzerine etkisinin araştırılması olup bu amaçla hem şekil bozukluğu hem de yırtılma açısından farklı plastisite modelleri sonlu elemanlar tahmin performansı açısından incelenmiştir.

\section{MALZEMENIN PLASTIK DAVRANIŞININ MODELLENMESI}

Bir malzeme şekil değiş̧imi sırasında önce elastik sonra plastik deplasmana uğramaktadır. Bir malzemenin elastik davranışı lineer olduğundan bu davranışı matematiksel olarak modellemek oldukça kolay bir işlemdir. Elastik bölgede gerilme ve gerinim değerleri arasındaki ilişki Denklem (1)'deki şekilde yazılabilir.

$$
\sigma=E . \varepsilon
$$

Burada E, elastisite modülünü temsil etmektedir. Malzemelerin plastik davranıșı non-lineerlik barındırdığından ve akma gerilmesinin gelişimi pekleşme ile temsil edildiğinden plastik davranışı modellemek elastik davranışta olduğu gibi kolay olmamaktadır. Plastik gerinimler, tüm yükleme geçmişine ve gerilme durumuna nasıl ulaşıldığına bağlıdır. Bir malzemenin genel gerilme durumunda plastik davranışlarını modelleyebilmek için, akmanın oluştuğu andaki gerilme bileşenleri arasındaki ilişkiyi açıklayan bir akma kriterine, gerilme ve gerinim oranı bileşenleri arasındaki ilişkiyi tanımlayan bir akma kuralına ve şekillendirme prosesi suresince başlangıç akma gerilmesinin gelişimini tanımlayan pekleşme kuralına ihtiyaç vardır [21]. Plastisite modelleri bu pekleşme kurallarını izotropik ve kinematik olmak üzere temelde iki farklı şekilde tanımlamaktadır. İzotropik pekleşme durumunda akma yüzeyinin asal gerilme uzayında yer değiştirmeden orantısal olarak büyüdügü̆, kinematik pekleşme durumunda ise akma yüzeyinin boyut değiştirmediği yalnızca asal gerilme uzayında öteleme gerilmesi miktarında konum değiştirdiği kabul edilmektedir.

Bu çalışma kapsamında plastik davranışı modelleyen plastisite modelleri izotropik malzeme-izotropik pekleşme, anizotropik malzeme-izotropik pekleşme ve anizotropik malzeme-kinematik pekleşme kabulü yapan modeller olarak üç ana grupta incelenmiştir. Bu modellerden izotropik malzeme-izotropik pekleșme kuralı kabulü yapan plastisite modelleri (Power Law) genellikle basit modeller olup günümüzde Holloman [22] ifadesi ile temsil edilebilmektedirler. Holloman ifadesinde gerilme ve plastik gerinim arasındaki ilişki Denklem (2)'deki şekilde yazılabilir. 


$$
\sigma=K . \varepsilon_{p}^{n}
$$

Burada K, mukavemet katsayısını ve n, pekleşme üstelini temsil etmektedir. Bu modellerden farklı olarak malzeme davranışını anizotropik olarak kabul eden, izotropik pekleşme temelli ve en sık kullanılan malzeme modelleri Barlat-89 [23] ve Hill-48 [24] modelleridir. Bu modellerden Barlat-89 modeli 1989 y1lında Barlat ve Lian tarafından sunulmuştur [23]. Bu model akma yüzeyi malzemenin anizotropik parametrelerine bağlı olarak elde etmektedir. Düzlem gerilme problemleri için Barlat-89 modeli şu şekilde yazılabilir.

$$
2 \sigma_{y}^{m}=a\left|K_{1}+K_{2}\right|^{m}+a\left|K_{1}-K_{2}\right|^{m}+c\left|K_{2}\right|^{m}
$$

Burada $\sigma_{\mathrm{y}}$ akma gerilmesi olup $\mathrm{K}_{1}$ ve $\mathrm{K}_{2}$ farklı yönlerdeki akma gerilmelerine, a ve c ise anizotropi katsayılarına bağlı parametrelerdir. Yine bu denklemde yer alan m üsteli ise malzemenin kristal kafes yapısı ile ilişkili olup yüzey merkezli kübik malzemeler için 8, hacim merkezli kübik malzemeler için ise 6 olarak kullanılması tavsiye edilmektedir [23]. Barlat dışında malzemeyi aniztropik olarak kabul eden ve günümüzde hala en sık kullanılan plastisite modeli 1948 yılında R. Hill tarafından ortaya atılmıştır [24]. Hill tarafından önerilen plastisite modeli düzlem gerilme için şu şekilde yazılabilmektedir.

$$
F\left(\sigma_{22}-\sigma_{33}\right)^{2}+G\left(\sigma_{33}-\sigma_{11}\right)^{2}+H\left(\sigma_{11}-\sigma_{22}\right)^{2}+2 L \sigma_{23}^{2}+2 M \sigma_{31}^{2}+2 N \sigma_{12}^{2}-1=0
$$

Burada $\sigma_{11}, \sigma_{22}$ ve $\sigma_{33}$ asal gerilmeler ve $\sigma_{12}, \sigma_{23}$ ve $\sigma_{31}$ ise kayma akma gerilmeleridir. F, G H, L, M ve N sabitleri ise malzemenin anizotropi katsayılarına veya akma gerilmelerine bağlı parametrelerdir.

$\mathrm{Bu}$ çalışmada incelenilen üçüncü grup plastisite modelli olarak ise kinematik pekleşme kabulü yapan modellerden günümüzde en sık kullanılan Yoshida-Uemori [25] kinematik pekleşme modeli tercih edilmiştir. Pekleşmeyi temsil edebilmek adına bu model, akma yüzeyi ve sınır yüzey olmak üzere iki yüzeye ihtiyaç duymaktadır. Şekillendirme prosesinde, akma yüzeyi boyut olarak değişmez fakat deformasyonla akma yüzeyinin merkez noktası hareket eder, sınır yüzeyi ise hem şekil olarak hem de konum olarak değişir. Şekil 1'de iki yüzeyli kinematik modelin şematik gösterimi görülmektedir. Burada, “O” akma yüzeyinin merkez noktasıdır, $\alpha^{*}$, akma yüzeyinin mevcut durumdaki merkezidir ve $\alpha$ ise sınır yüzeyin merkezidir. $\beta$, iki yüzeyin merkez nokraları arasındaki ilişkiyi temsil etmektedir. Y, akma yüzeyinin boyutudur ve deformasyon süresince değişmemektedir. $\mathrm{B}+\mathrm{R}$, sınır yüzeyinin boyutunu temsil etmektedir, $\mathrm{R}$ izotropik pekleşme ile ilişkilidir. Yoshida nonlineer pekleşme modeli Bauschinger etkisini ve sac metal şekillendirme proseslerindeki malzeme davranışını tanımlamakta başarılı bir modeldir. Yeni nesil yüksek mukavemetli çelikler için de başarılı sonuçlar verebilmektedir. Şekil 2'de Yoshida kinematik pekleşme modeli ile tahmin edilen bir malzeme davranışı gerilme-gerinim eğrisi üzerinde gösterilmiştir.

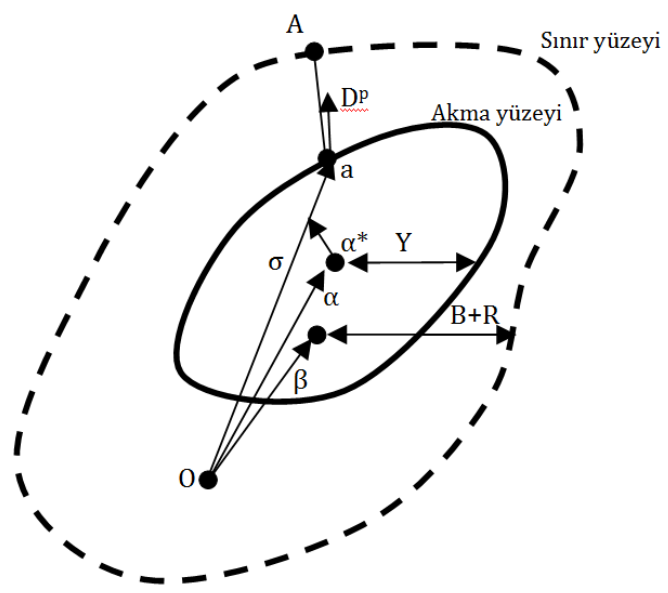

Şekil 1. İki yüzeyli modelin şematik gösterimi [26] 


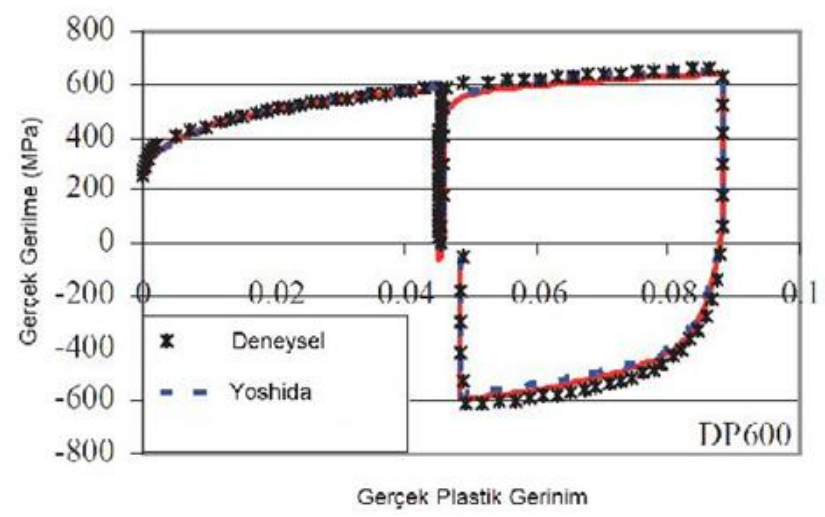

Şekil 2. Yoshida nonlineer kinematik pekleşme modeli ile malzeme davranışının tahmini [27]

\section{UYGULAMA ÇALIŞMALARI}

Bu çalışma kapsamında yukarıda anlatılanlar doğrultusunda plastisite modellerinden Power Law, Hill48, Barlat-89 ve Yoshida-Uemori modellerinin sac metal şekillendirme sonlu elemanlar analizleri tahmin performansı üzerindeki etkileri incelenmiştir. Bu kapsamda sac metal şekillendirme işlemlerinden derin çekme, kare kutu çekme ve V-kalıpta eğme prosesleri kullanılmıştır. Bu proseslerin tercih nedeni her bir prosesin farklı bir karakterizasyona sahip olmasıdır. Bu proseslerde toplamda 4 adet malzeme kullanılmış olup bu malzemeler DP600, DP980, AA5754 ve DC05'tir. Plastisite modellerinin ihtiyaç duyduğu mekanik özellikler mekanik testler vasıtası ile elde edilebilmektedir. $\mathrm{Bu}$ çalışma kapsamında kullanılan tüm malzemelerin yine bu çalışmada kullanılan tüm plastisite modellerine ait parametreler Tablo 1'de özetlenmiştir. Çalışma kapsamında yapılan sonlu elemanlar analizlerinde Dynaform ticari yazılımı tercih edilmiştir.

Tablo 1. Çalışma kapsamında kullanılan malzemelerin malzeme modellerine göre mekanik özellikleri [28-30]

\begin{tabular}{|c|c|c|c|c|}
\hline & DP600 & DP980 & DC05 & AA5754 \\
\hline \multicolumn{5}{|c|}{ POWER LAW MALZEME MODEL PARAMETRELERİ } \\
\hline Mukavemet katsayısı (MPa) & 1080,7 & 1142 & 538,5 & 425 \\
\hline Pekleşme üsteli & 0,152 & 0,12 & 0,25 & 0,29 \\
\hline \multicolumn{5}{|c|}{ HILL-48 MALZEME MODEL PARAMETRELERİ } \\
\hline Akma gerilmesi (MPa) & 420 & 652 & 171 & 142,5 \\
\hline Elastisite modülü (GPa) & 206 & 207 & 191 & 69 \\
\hline Mukavemet katsayısı (MPa) & 1080,7 & 1142 & 538,5 & 425 \\
\hline Pekleşme üsteli & 0,15 & 0,12 & 0,25 & 0,29 \\
\hline Ortalama anizotropi & 0,89 & 0,74 & 1,57 & 0,61 \\
\hline \multicolumn{5}{|c|}{$\begin{array}{l}\text { BARLAT-89 MALZEME MODEL PARAMETRELERİ } \\
\end{array}$} \\
\hline Akma gerilmesi (MPa) & 420 & 652 & 171 & 142,5 \\
\hline Elastisite modülü (GPa) & 206 & 207 & 191 & 69 \\
\hline Hadde yönünde anizotropi & 0,82 & 0,85 & 1,96 & 0,5 \\
\hline Hadde yönüne $45^{01}$ de anizotropi & 0,92 & 0,70 & 1,35 & 0,66 \\
\hline Hadde yönüne dik anizotropi & 0,91 & 0,72 & 1,62 & 0,61 \\
\hline Kristal yapı üsteli (m) & 6 & 6 & 6 & 8 \\
\hline \multicolumn{5}{|c|}{ YOSHIDA-UEMORI MALZEME MODEL PARAMETRELERI } \\
\hline $\mathrm{B}(\mathrm{MPa})$ & 555 & 775,2 & 168 & 159,4 \\
\hline $\mathrm{c}$ & 200 & 239,2 & 100 & 75,08 \\
\hline $\mathrm{R}_{\text {sat }}(\mathrm{MPa})$ & 190 & 109,8 & 200 & 160 \\
\hline $\mathrm{K}(\mathrm{MPa})$ & 1080,7 & 1142 & 538,5 & 425 \\
\hline $\mathrm{b}(\mathrm{MPa})$ & 110 & 74 & 13 & 81,25 \\
\hline $\mathrm{h}$ & 0,9 & 0,82 & 1,6 & 0,6 \\
\hline
\end{tabular}

\section{A. Derin Çekme}

Derin çekme prosesi bir malzemenin derin çekilebilirlik sınırını elde etmek adına kullanılan bir benzetim testi olmakla birlikte aynı zamanda bir üretim yöntemidir. Bu proseste daire kesitli bir sac açınımı silindirik bir zımba vasıtası ile çekme işlemine tabi tutulmaktadır. Bu çalışmada çift fazlı çelik grubundan DP600 ve DP980 malzemelerine ait bir derin çekme prosesinin sonlu elemanlar analizleri gerçekleştirilmiş ve farklı malzeme modellerinin deneysel sonuca [31] yakınsama performansları incelenmiştir. Bu kapsamda deneysel sonuçlarla 
kıyaslama limit çekme oranı (LÇO) ile gerçekleştirilmiştir. Limit çekme oranı derin çekilebilirliğin maksimum olduğu sac açınım çapının zımba çapına oranı olarak tanımlanmaktadır. Limit çekme oranı şu şekilde yazilabilmektedir.

$$
L C ̧ O=\frac{D_{s}}{D_{z}}
$$

Burada $D_{\mathrm{s}}$ sac açınım çapını, $\mathrm{D}_{\mathrm{z}}$ zımba çapını temsil etmektedir.

Çalışmada dört farklı malzeme modeli ve iki farklı malzeme kullanılarak simülasyonlar gerçekleştirilmiş ve malzeme modellerine göre LÇO hesaplanmış ve deneysel sonuç ile kıyaslanmıştır. Sonlu elemanlar analiz modeli Şekil 3'te verilmiştir. Proses parametresi olarak parça tutucu kuvvet deneysel çalışma [31] referans alınarak DP600 için 23 kN ve DP980 için 30 kN olarak kullanılmıştır. Bunun dışında sürtünme katsayısı 0,125 ve kalıp hızı $2000 \mathrm{~mm} / \mathrm{s}^{\prime}$ dir. Sonlu elemanlar hesaplama parametreleri ise Tablo 2'de verilmiştir. Gerçekleştirilen simülasyonlar sonrasında LÇO'lar her model için tespit edilmiştir. Deneysel sonuçlarla kıyaslama Tablo 3 'te görülmektedir. Tablodan görüldüğü üzere her model derin çekilebilirliği yakın tahmin etse de kinematik pekleşme davranışını modelleyen Yoshida-Uemori modeli her iki malzeme için de en yakın sonucu elde etmiştir.

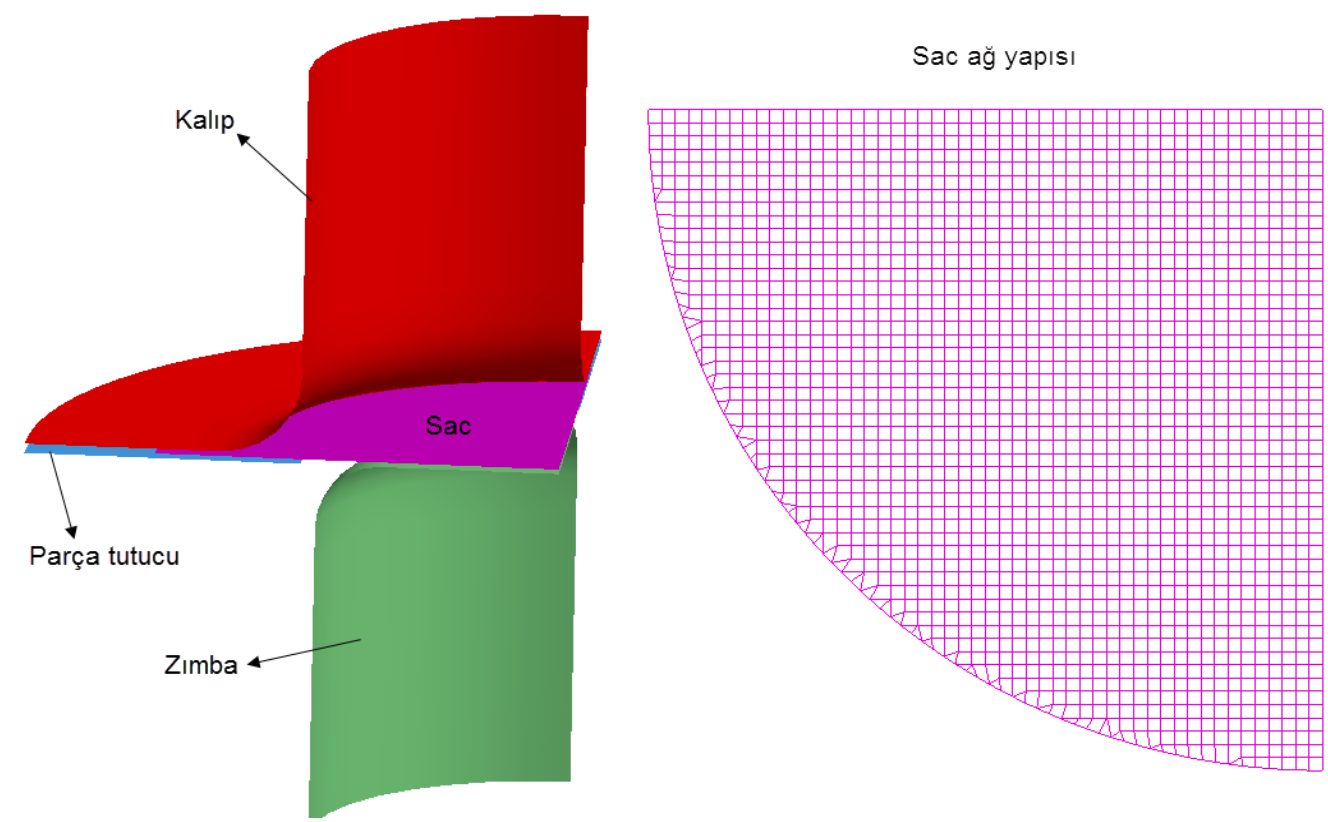

Şekil 3. Derin çekme sonlu elemanlar modeli ve sac açınım ağ yapısı

Tablo 2. Derin çekme simülasyonu hesaplama parametreleri

\begin{tabular}{ll}
\hline Parametre & Değer \\
\hline Sac eleman boyutu & $1 \mathrm{~mm}$ \\
Sac eleman sayısı & 1943 \\
Eleman formülasyonu & Tam integrasyonlu kabuk eleman \\
İntegrasyon nokta sayısı & 7 \\
\hline
\end{tabular}

Tablo 3. Derin çekme sonlu elemanlar malzeme modellerinin tahmin performanslarının karşılaştırılması

\begin{tabular}{llll}
\hline \multicolumn{4}{c}{ LÇO Oranları (mm) } \\
\hline DP600 & \multicolumn{2}{c}{ DP980 } \\
\hline Deneysel & 3,33 & Deneysel & 3,33 \\
Power Law & 3,60 & Power Law & 3,84 \\
Hill-48 & 3,70 & Hill-48 & 3,82 \\
Barlat-89 & 3,69 & Barlat-89 & 3,71 \\
Yoshida-Uemori & 3,51 & Yoshida-Uemori & 3,51 \\
\hline
\end{tabular}




\section{B. Kare Kutu Çekme}

Kare kutu çekme benzetimi sac metallerin şekillendirilebilirliklerinin en efektif tespit edilebildiği proseslerin başında gelmektedir. Gerek yırtılma yüksekliği gerekse de kırışma ve kulaklanma durumları etkin bir şekilde gözlemlenebilmektedir. Bu nedenle malzeme modellerinin etkisinin araştırılması adına çalışmada ikinci proses olarak kare kutu çekme seçilmiştir. Bu kapsamda malzeme olarak AA5754 alüminyum alaşımı kullanılarak bir kare kutu çekme işlemine ait sonlu elemanlar analizleri farklı malzeme modelleri ile gerçekleştirilmiştir. Deneysel referans olarak yırtılma yüksekliği alınmış olup sonlu elemanlar analizlerinden de yırtılma yükseklikleri tespit edilmiştir. Sonlu elemanlar analizlerinde yırtılma yüksekliği şekillendirme sınır diyagramında yırtılma sınırındaki kalıp ilerleme mesafesi olarak alınmıştır (Şekil 4). Eksenel simetriden dolayı 1/4 model kullanılmış olup proses parametresi olarak $55 \mathrm{kN}$ parça tutucu kuvvet, 0,125 sürtünme katsayısı ve $2000 \mathrm{~mm} / \mathrm{s} \mathrm{kalıp} \mathrm{hızı}$ uygulanmıştır. Prosesin sonlu elemanlar modeli Şekil 5 'te, sonlu elemanlar hesaplama parametreleri ise Tablo 5 'te verilmiştir. Yapılan simülasyonlar sonrasında her malzeme modeli ile elde edilen yırtılma yüksekliklerinin deneysel sonuç [32] ile kıyaslanması Tablo 6'da görülmektedir.

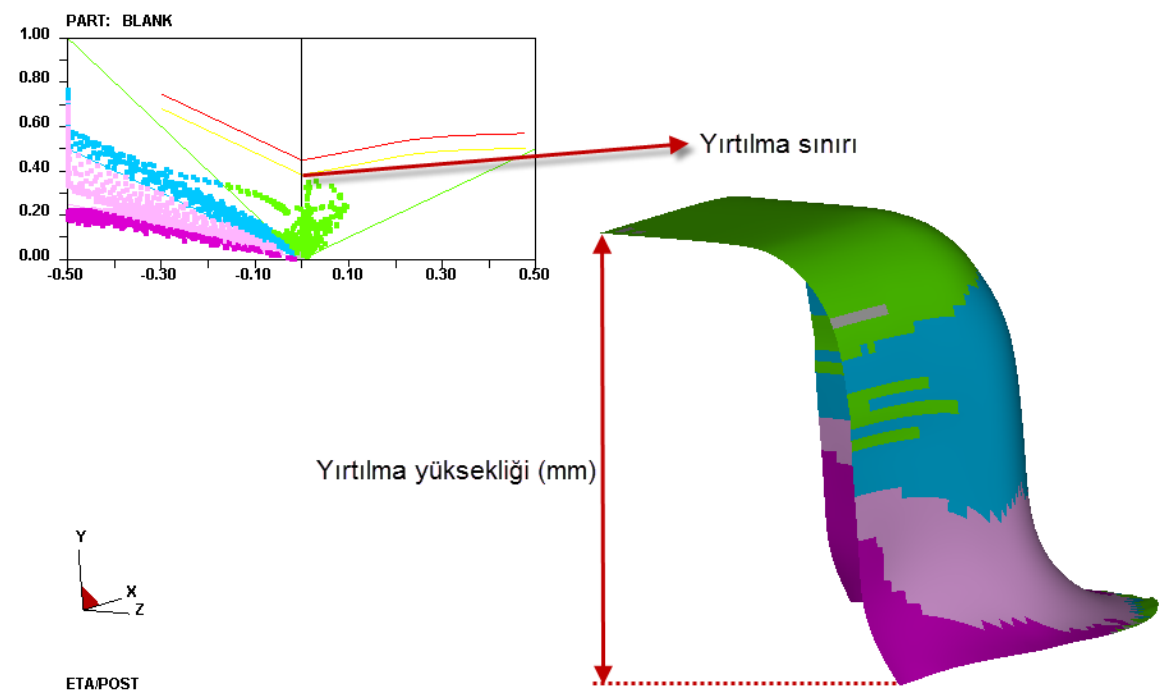

Şekil 4. Kare kutu çekme prosesi için sonlu elemanlar analizlerinde yırtılma yüksekliğinin tespiti
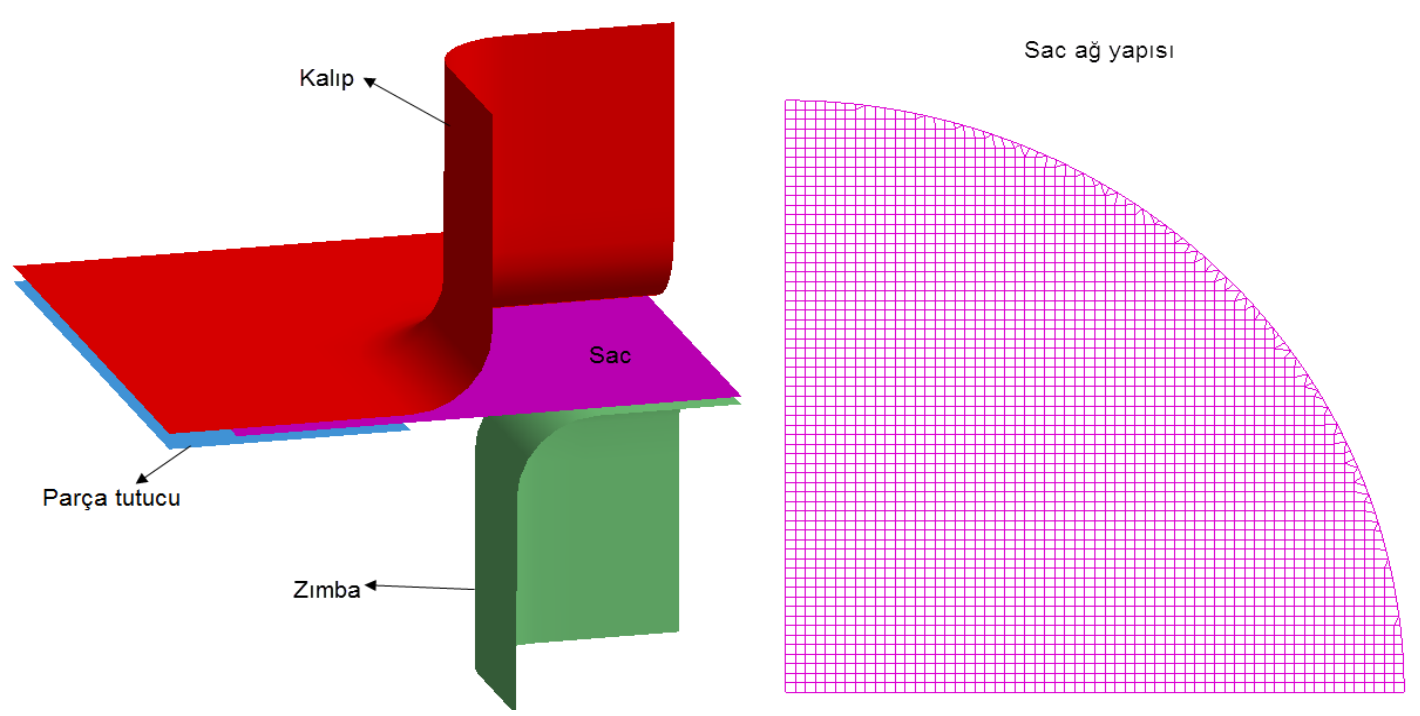

Şekil 5. Kare kutu çekme sonlu elemanlar modeli ve sac açınım ağ yapısı 
Tablo 5. Kare kutu çekme simülasyonu hesaplama parametreleri

\begin{tabular}{ll}
\hline Parametre & Değer \\
\hline Sac eleman boyutu & $1 \mathrm{~mm}$ \\
Sac eleman sayısı & 3042 \\
Eleman formülasyonu & Tam integrasyonlu kabuk eleman \\
İntegrasyon nokta sayısı & 7 \\
\hline
\end{tabular}

Tablo 6. Kare kutu çekme sonlu elemanlar malzeme modellerinin tahmin performanslarının karşılaştırılması

\begin{tabular}{ll}
\hline \multicolumn{2}{c}{ Yırtılma Yüksekliği (mm) } \\
\hline \multicolumn{2}{c}{ AA 5754 } \\
\hline Deneysel & 39,2 \\
Power Law & 42,7 \\
Hill-48 & 42,1 \\
Barlat-89 & 41,8 \\
Yoshida-Uemori & 39,5 \\
\hline
\end{tabular}

\section{V-Kalipta Ĕgme}

Benzetim testleri malzemelerin şekillendirilebilirliklerinin yanı sıra form verme işlemi sonrasında şekil bozukluklarını da tespit edebilmektedir. Bu anlamda en sık kullanılan benzetim testlerinin başında gelen V-kalıpta eğme testi çalışmanın üçüncü prosesi olarak seçilmiştir. Bu adımda malzeme modellerinin şekil bozukluğu üzerine etkileri tespit edilecektir. Bu amaçla $60^{\circ}$ açıya sahip bir V-kalıpta eğme prosesi [33] deneysel referans olarak kullanılmış olup, şekillendirme sonrasındaki geri esneme açısı sonlu elemanlar doğrulamasında kullanılan parametre olarak belirlenmiştir. Burada geri esneme açısı, form verme işlemi sonrasında çıkan ürünün ara açısı ile kalıp açısının farkı olarak tanımlanmıştır. Malzeme olarak DP600 ve DC05 çelikleri kullanılmıştır. Bu doğrultuda prosese ait sonlu elemanlar modeli simetri koşulundan dolayı 1/2 model olarak oluşturulmuş (Şekil 6) ve farklı malzeme modelleri ile simülasyonlar gerçekleştirilerek sonuçlar deneysel sonuç ile kıyaslanmıştır. Simülasyonlarda kullanılan sonlu elemanlar hesaplama parametreleri Tablo 7'de verilmiş olup proses parametresi olarak sürtünme katsayısı 0,125 ve kalıp hızı 2000 mm/s olarak kullanılmıştır. Bu proses bir serbest bükme işlemi olduğundan kalıp takımları arasında parça tutucu yer almamaktadır. Simülasyon sonuçları ile deneysel sonuçların karşılaștııılması Tablo 8'de görülmektedir. Tahmin performansı olarak en yakın sonucu Yoshida-Uemori modeli vermekle birlikte bu proseste DC05 malzemesi için Barlat-89 modeli başarılı bir şekillendirme işlemi gerçekleştirememiştir. Bu durum Şekil 7'de verilmiş̧ir.

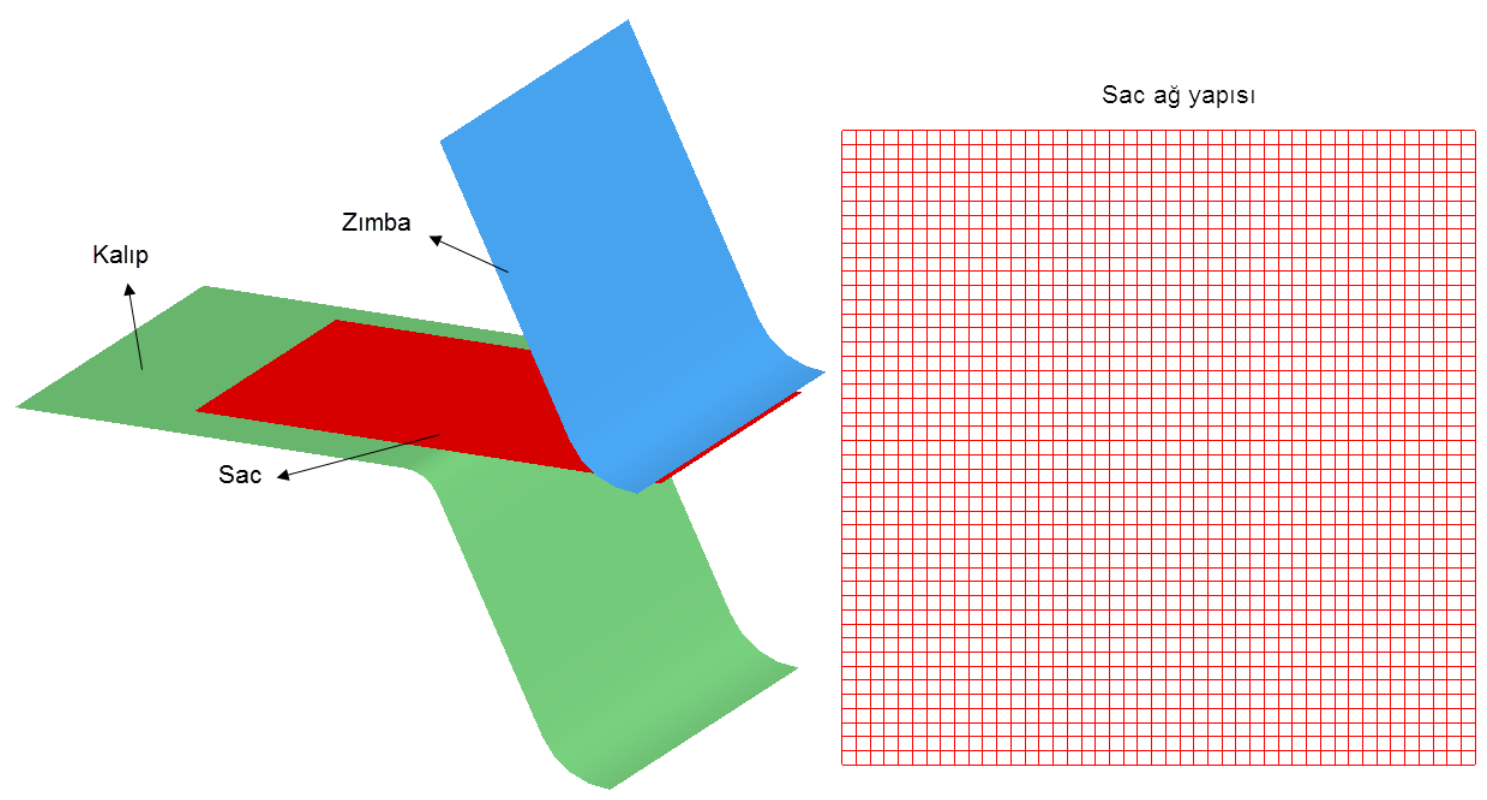

Şekil 6. V-kalıpta eğme sonlu elemanlar modeli ve sac açınım ağ yapısı 
Tablo 7. V-kalıpta eğme simülasyonu hesaplama parametreleri

\begin{tabular}{ll}
\hline Parametre & Değer \\
\hline Sac eleman boyutu & $1 \mathrm{~mm}$ \\
Sac eleman sayısı & 2025 \\
Eleman formülasyonu & Tam integrasyonlu kabuk eleman \\
İntegrasyon nokta sayısı & 7 \\
\hline
\end{tabular}

Tablo 8. V-kalıpta eğme sonlu elemanlar malzeme modellerinin tahmin performanslarının karşılaştırılması

\begin{tabular}{|c|c|c|c|}
\hline \multicolumn{4}{|c|}{ Geri Esneme $\left(^{\circ}\right)$} \\
\hline \multicolumn{2}{|l|}{ DP600 } & \multicolumn{2}{|c|}{ DC05 } \\
\hline Deneysel & 7,33 & Deneysel & 2,1 \\
\hline Power Law & 5,90 & Power Law & 0,48 \\
\hline Hill-48 & 3,98 & Hill-48 & 2,96 \\
\hline Barlat-89 & 6,20 & Barlat-89 & Başarısız \\
\hline Yoshida-Uemori & 7,06 & Yoshida-Uemori & 1,72 \\
\hline
\end{tabular}

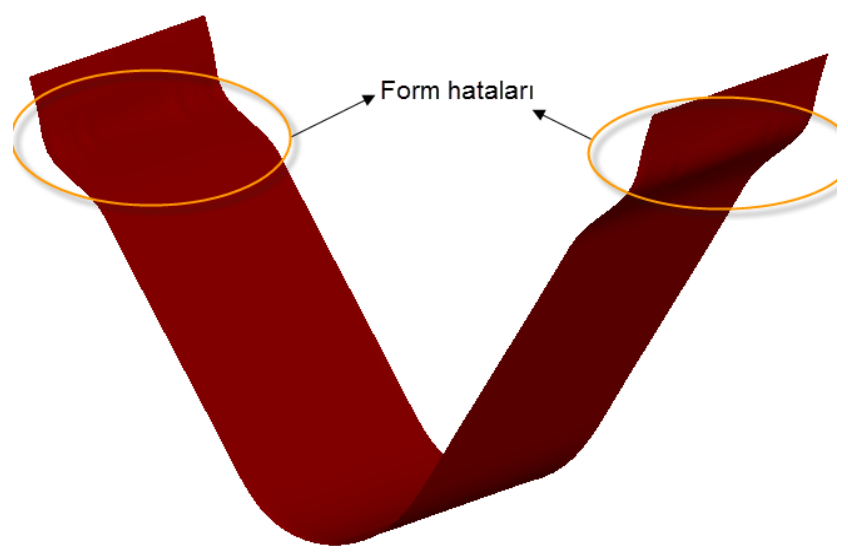

Şekil 7. Barlat-89 modelinin DC05 malzemesi için gerçekleştirdiği başarısız tahminde gözlemlenen form hataları

\section{SONUÇLAR VE TARTIŞMA}

Yapılan çalışmada sac metal sonlu elemanlar tahmin performansına malzemelerin plastik davranışı modelleyen malzeme modellerinin etkisinin incelenmesi amaçlanmıştır. Bu amaç doğrultusunda hem yeni nesil yüksek mukavemetli (DP600, DP980) hem de düşük karbonlu çelik (DC05) grubundan ve demir dışı malzeme grubundan (AA5754) malzemeler seçilerek malzeme modeli etkisi irdelenmiştir. Proses olarak ise şekillendirilebilirlik temelli olarak derin çekme ve kare kutu çekme, şekil bozukluğu temelli olarak ise V-kalıpta eğme prosesleri kullanılmıştır. Her malzeme ve her proses için dört farklı malzeme modeli kullanılarak simülasyonlar gerçekleştirilmiştir. Malzeme modelleri temelde izotropik malzeme-izotropik pekleşme kabullü (Power Law), anizotropik malzeme - izotropik pekleşme kabullü (Hill-48, Barlat-89) ve anizotropik malzeme kinematik pekleşme kabullü (Yoshida-Uemori) olarak gruplandırılmıştır. Simülasyonlar sonrasında elde edilen sonuçlar ilgili proseslerin deneysel verileri ile karşılaş̧ırılarak modellerin tahmin performansları irdelenmiştir.

Elde edilen sonuçlar tartışıldığında şu bulgulara varılmaktadır:

a) Malzeme modelleri, ihtiyaç duydukları parametreler bakımından incelendiğinde kinematik pekleşme modelinin daha fazla parametreye ihtiyaç duyduğu görülmektedir. Bu bakımdan bu tarz bir model kullanabilmek için daha fazla test ya da optimizasyon adımlarının gerçekleştirilmesi gerekmektedir. Bu bakımdan kinematik pekleşme modelleri diğer modellere göre daha fazla kullanım zorluğuna sahiptirler.

b) Derin çekme prosesinde her malzeme modeli deneysel modele yakın sonuç vermekle birlikte en yakın sonuçlar kinematik pekleşme modeli olan Yoshida-Uemori modeli ile elde edilmiştir. Her iki çift fazlı çelik için de başarılı tahminler gerçekleştirilmiştir.

c) Kare kutu çekme prosesinde en yakın sonuç neredeyse deneysel yırtılma yüksekliğini yakalayabilen Yoshida-Uemori modeli ile elde edilmiştir. Diğer modellerin deneysel yırtılma yüksekliği ile farkları 2,5-3,5 mm 
mertebelerinde iken Yoshida-Uemori modelinin deneysel modelle fark1 0,2 mm'dir. Bu proseste kinematik malzeme modelinin alüminyum alaşımları için de doğru tahmin verebildiği tespit edilmiştir.

d) V-kalıpta eğme deneyi açısından sonuçlar incelendiğinde yine şekil bozukluğunu Yoshida-Uemori modeli deneysel sonuca en yakın tahmini vermiştir. Şekil bozukluğunda kinematik pekleşmenin etkisi daha fazla gözlemlenmiş olup modeller arasındaki en büyük farkın bu proseste ortaya çıktığı tespit edilmiştir. Buna ek olarak Barlat-89 modeli bu prosesin şekillendirme adımını dahi tahmin edememiştir. Barlat-89 modelinin alüminyum alaşımları için daha uygun bir model olduğu literatürdeki çalışmalarla doğrulanmıştır [34, 35]. Bu durum yapılan çalışmada da gözlemlenmiş olup çelik malzemelerde Barlat-89 modeli özellikle şekil bozukluğu açısından başarısız olmuştur.

Sonuçlar özetlendiğinde, kinematik pekleşme kabulü yapan malzeme modellerinin sonlu elemanlar analizlerinde daha hassas tahminler yapabildikleri tespit edilmiştir. Bu durum, kinematik pekleşme modellerinin Bauschinger etkisini dikkate alabilme kabiliyetlerinin bulunmasının ve sac metal şekillendirme işlemlerinde büküm bölgelerinde de bu durumun etkin olmasının bir sonucu olduğu düşünülmektedir. Tahmin hassasiyetinde malzeme modellerinin şekil bozukluğu üzerinde daha baskın bir etkiye sahip oldukları tespit edilmiştir. Sonuç olarak sac metal sonlu elemanlar analizlerinde malzeme modelinin tespiti özellikle şekil bozukluğu tahminlerinde büyük rol oynamaktadır.

\section{KAYNAKLAR}

[1] Hattalli, V. L., \& Srivatsa, S. R. (2018). Sheet metal forming processes-recent technological advances. Materials Today: Proceedings, 5(1), 2564-2574.

[2] Lal, R. K., Choubey, V. K., Dwivedi, J. P., \& Kumar, S. (2018). Study of factors affecting Springback in sheet metal forming and deep drawing process. Materials Today: Proceedings, 5(2), 4353-4358.

[3] Ahmed, M. (2018). Adaptive finite element simulation of sheet forming process parameters. Journal of King Saud University-Engineering Sciences, 30(3), 259-265.

[4] Wang, X., Li, L., Deng, L., Jin, J., \& Hu, Y. (2015). Effect of forming parameters on sheet metal stability during a rotary forming process for rim thickening. Journal of Materials Processing Technology, 223, 262273.

[5] Kumara, A., Gulatia, V., \& Kumarb, P. (2018). Effects of Process Parameters on Surface Roughness in Incremental Sheet Forming. Materials Today: Proceedings, 5(14), 28026-28032.

[6] Shi, Y., Jin, H., \& Wu, P. D. (2018). Analysis of cup earing for AA3104-H19 aluminum alloy sheet. European Journal of Mechanics-A/Solids, 69, 1-11.

[7] Wang, X., \& Cao, J. (2000). An analytical prediction of flange wrinkling in sheet metal forming. Journal of Manufacturing Processes, 2(2), 100-107.

[8] Son, Y. K., Ko, D. C., \& Kim, B. M. (2015). Prediction of delamination and tearing during stamping of polymer-coated metal sheet. Journal of Materials Processing Technology, 220, 146-156.

[9] Dewang, Y., Panthi, S. K., \& Hora, M. S. (2018). Some aspects of blank holding force in stretch flanging process. Materials Today: Proceedings, 5(2), 6789-6798.

[10] Leminen, V., Matthews, S., Pesonen, A., Tanninen, P., \& Varis, J. (2018). Combined effect of blank holding force and forming force on the quality of press-formed paperboard trays. Procedia Manufacturing, 17, 11201127.

[11] Wang, Y. G., Huang, G. S., Liu, D. K., Lin, C. H. E. N., Han, T. Z., Jian, P. E. N. G., \& Pan, F. S. (2016). Influence of blank holder type on drawability of 5182-O aluminum sheet at room temperature. Transactions of Nonferrous Metals Society of China, 26(5), 1251-1258.

[12] Ozsoy, M., Esener, E., Ercan, S., \& Firat, M. (2014). Springback predictions of a dual-phase steel considering elasticity evolution in stamping process. Arabian Journal for Science and Engineering, 39(4), 3199-3207. 
[13] Zhang, R., Shao, Z., \& Lin, J. (2018). A review on modelling techniques for formability prediction of sheet metal forming. International Journal of Lightweight Materials and Manufacture, 1(3), 115-125.

[14] Kim, J. H., Lee, M. G., Kang, J. H., Oh, C. S., \& Barlat, F. (2017). Crystal plasticity finite element analysis of ferritic stainless steel for sheet formability prediction. International Journal of Plasticity, 93, 26-45.

[15] Zahedi, A., Dariani, B. M., \& Mirnia, M. J. (2019). Experimental determination and numerical prediction of necking and fracture forming limit curves of laminated $\mathrm{Al} / \mathrm{Cu}$ sheets using a damage plasticity model. International Journal of Mechanical Sciences, 153, 341-358.

[16] Panthi, S. K., Ramakrishnan, N., Pathak, K. K., \& Chouhan, J. S. (2007). An analysis of springback in sheet metal bending using finite element method (FEM). Journal of Materials Processing Technology, 186(1-3), 120-124.

[17] Yao, H., Liu, S. D., Du, C., \& Hu, Y. (2002). Techniques to improve springback prediction accuracy using dynamic explicit FEA codes. SAE Transactions, 111, 100-106.

[18] Turon, A., Davila, C. G., Camanho, P. P., \& Costa, J. (2007). An engineering solution for mesh size effects in the simulation of delamination using cohesive zone models. Engineering fracture mechanics, 74(10), $1665-1682$.

[19] Bruschi, S., Altan, T., Banabic, D., Bariani, P. F., Brosius, A., Cao, J., ... \& Tekkaya, A. E. (2014). Testing and modelling of material behaviour and formability in sheet metal forming. CIRP Annals, 63(2), 727-749.

[20] Kuwabara, T., Hashimoto, K., Iizuka, E., \& Yoon, J. W. (2011). Effect of anisotropic yield functions on the accuracy of hole expansion simulations. Journal of Materials Processing Technology, 211(3), 475-481.

[21] Slater, R. C. (1977). Engineering and Plasticity: Theory and Application to Metal Forming Processes. Macmillan International Higher Education, London, UK, 419.

[22] Holloman, J. H. (1945). Tensile Deformation, Transactions of the American Institue of Mining and Metallalurgical Engineers, 162:268-290.

[23] Barlat, F., Lian, J. (1989). Plastic behaviour and stretchability of sheet metals (Part I): A yield function for orthotropic sheet under plane stress conditions, International Journal of Plasticity, 5:51-56.

[24] Hill, R. (1948). A theory of the yielding and plastic flow of anisotropic metals, Proc. Roy. Soc. London, 281297.

[25] Yoshida, F., \& Uemori, T. (2002). A model of large-strain cyclic plasticity describing the Bauschinger effect and workhardening stagnation. International journal of plasticity, 18(5-6), 661-686.

[26] Ls-Dyna Theoretical Manual. (1998). Livermore Software Technology Corporation.

[27] Shi, M. F., Zhu, X., Xia, C., \& Stoughton, T. (2008). Determination of nonlinear isotropic/kinematic hardening constitutive parameters for AHSS using tension and compression tests. In NUMISHEET Conference, Interlaken, Switzerland, Sept, 1-5.

[28] Aryanpour A., \& Green D. E. Evaluation of LS-DYNA® Material Models for the Analysis of Sidewall Curl in Advanced High Strength Steels. 12th International LS-DYNA ${ }^{\circledR}$ Users Conference, Canada.

[29] Toros, S. (2016). Parameters Determination of Yoshida Uemori Model Through Optimization Process of Cyclic Tension-Compression Test and V-Bending Springback. Latin American Journal of Solids and Structures, 13(10), 1893-1911.

[30] Pipard, J. M., Balan, T., Abed, Meraim, F., \& Lemoine, X. (2013). Elasto-visco-plastic modeling of mild steels for sheet forming applications over a large range of strain rates. International Journal of Solids and Structures, 50, 2691-2700. 
[31] Bandyopadhyay, K., Panda, S. K., Saha, P., \& Padmanabham, G. (2015). Limiting drawing ratio and deep drawing behavior of dual phase steel tailor welded blanks: FE simulation and experimental validation. Journal of materials processing technology, 217, 48-64.

[32] Demirci, H. İ., Esner, C., \& Yaşar, M. (2008). Effect of the blank holder force on drawing of aluminum alloy square cup: Theoretical and experimental investigation. Journal of Materials Processing Technology, 206, 152-160.

[33] Uslu, E. (2014). Sac Malzemelerin Bükülmesinde Geri Yaylanma Davranışının Araştırılması. Yüksek Lisans Tezi, Fırat Üniversitesi, Fen Bilimleri Enstitüsü, Elazı ̆̆.

[34] Lazarescu, L., Ciobanu, I., Nicodim, I. P., Comsa, D. S., \& Banabic, D. (2013). Effect of the mechanical parameters used as input data in the yield criteria on the accuracy of the finite element simulation of sheet metal forming processes. Key Engineering Materials, 554, 204-209.

[35] Tang, B., Lu, X., Wang, Z., \& Zhao, Z. (2010). Springback investigation of anisotropic aluminum alloy sheet with a mixed hardening rule and Barlat yield criteria in sheet metal forming. Materials \& design, 31(4), 20432050. 